\title{
Kissing Stents for Treatment of Aortoiliac Disease.
}

\author{
G.M. Mokbul Hossain ${ }^{1}$, Naresh Chandra Mandal ${ }^{2}$, Nirmal Kanti Dey ${ }^{3}$, Abdullah Al-Mamun ${ }^{4}$, Motiur Rahman ${ }^{5}$ \\ Rakibul Hasan 6
}

\begin{abstract}
Objectives: To determine technical and clinical success of kissing stents for aortoiliac occlusive disease.

Design: Retrospective study.

Venue: Different private centers in Dhaka City.

Subjects: Patients presenting with intermittent claudication (IC) or critical limb ischaemia (CLI) due to aortoiliac disease.

Methods: Balloon or self expanding kissing stents with or without predilatation depending upon the nature of the disease, was inserted via bilateral retrograde
\end{abstract}

femoral approach. Patients were followed up clinically and by ankle brachial index (ABI) and Duplex study.

Results: Technical and clinical success was achieved in all of 34 cases. All patients with CLI improved and ulcerated limbs showed complete healing. During follow-up 3 patients died and 1 patient required major amputation at 3 months.

Conclusion: Kissing stents implantation is a safe and alternative treatment for aortoiliac disease. It is cosmetic, requires short hospital stay. No incision, regional or general anesthesia is needed.

Key Words: Aortoiliac disease, Kissing stent, TASC classification.

\section{Introduction:}

Traditional treatment of aortoiliac stenoses or occlusions is surgery. For focal lesions, aortoiliac endarterectomy and for more diffuse lesions aortobifemoral bypass are the choice. The durability of these procedures is excellent (85\% to $90 \%$ at 5 years). ${ }^{1}$ Reported operative mortality is $3.3 \%$, whereas perioperative morbidity is $8.3 \% .^{1-3}$ In spite of excellent patency rates, surgery is associated with anesthesia, prolonged hospitalization and recovery time, and loss of sexual function. Kissing balloon angioplasty is an alternative to surgery ${ }^{1,2}$, but there is significant incidence of dissection, thrombosis and residual stenosis $^{4,5}$. The kissing stent technique which involves simultaneous implantation of two stents at aortic

1. Assistant Professor, Department of Vascular Surgery, National Institute of Cardiovascular Diseases (NICVD), Dhaka.

2. Associate Professor, Department of Vascular Surgery, NICVD, Dhaka.

3. Resident Surgeon, Department of Vascular Surgery, NICVD, Dhaka.

4. Assistant Register, Department of Vascular Surgery, NICVD, Dhaka.

5. Assistant Register, Department of Vascular Surgery, NICVD, Dhaka.

6. Postgraduate Fellow, Department of Cardiac Surgery, Bangabandhu Sheikh Mujib Medical University (BSMMU), Dhaka. bifurcation is supposed to overcome these drawbacks. ${ }^{6,7}$ With the refinement in stent technology, kissing stent

technique has largely replaced kissing balloon angioplasty for the treatment of aortoiliac occlusive disease.

\section{Methods:}

This is a retrospective study. Patients who underwent aortoiliac kissing stents were included in this study. Only lesions involving aortoiliac segment was included. Isolated unilateral or bilateral iliac lesions were excluded from the study. Associated aortic aneurysm was also excluded. Informed written consent regarding procedural details, risks and complications were taken from each patient.

\section{Procedure:}

All the patients were retrogradely approached via bilateral common femoral artery (CFA). 7F sheath was placed in both CFA. The lesion was crossed using 0.035 inch hydrophilic guide wire (Roadrunner ${ }^{\circ}$ PC - Cook Medical, Bloomington, IN 47402-4195 USA) with or without the use of $4 \mathrm{~F}$ straight diagnostic catheters. Preprocedural angiogram was done using 5F nonselective catheters. When lesions were crossed, 2 stents were advanced 
bilaterally over the guidewires placed side by side in aortic bifurcation and implanted simultaneously (FiguresI, II, III).

Direct stenting was preferred over primary stenting. Predilatation was performed using 4 to $5 \mathrm{~mm}$ balloon dilatation catheter. The stent model and size were chosen based on lesion characteristics and availability. Balloon expandable stents were Neptune (Balton, Poland, $\mathrm{n}=52$ ). Self expandable stents were complete SE (Medtronic USA, $n=16)$. Post dilatation was performed after implantation of all self-expanding stents. During the procedure, 5000 units of unfractionated heparin was used intra-arterially or intravenously. Clopidogrel $75 \mathrm{mg}$ and aspirin $75 \mathrm{mg}$ per day were prescribed to all patients for continuous use.

\section{Follow-Up:}

Follow up included clinical examination, measurement of ankle brachial index (ABI) and Duplex study.

\section{Definitions:}

Technical success was defined as the absence of $<30 \%$ residual stenosis on postprocedural angiography at the treated segment. Clinical success was defined by an improvement of walking distance (intermittent claudication).

Complications were defined as minor if no or only minor therapy with overnight observation was required or major when major therapy, prolonged hospitalization, or an unplanned increase in the level of care was necessary.

Primary patency was defined as a patent stent without any reintervention. Primary assisted patency was defined as a patent stent after endovascular reintervention but without occlusion at any time. Secondary patency was defined as a patent stent after occlusion, with patency ending with an untreated or surgically treated occlusion.
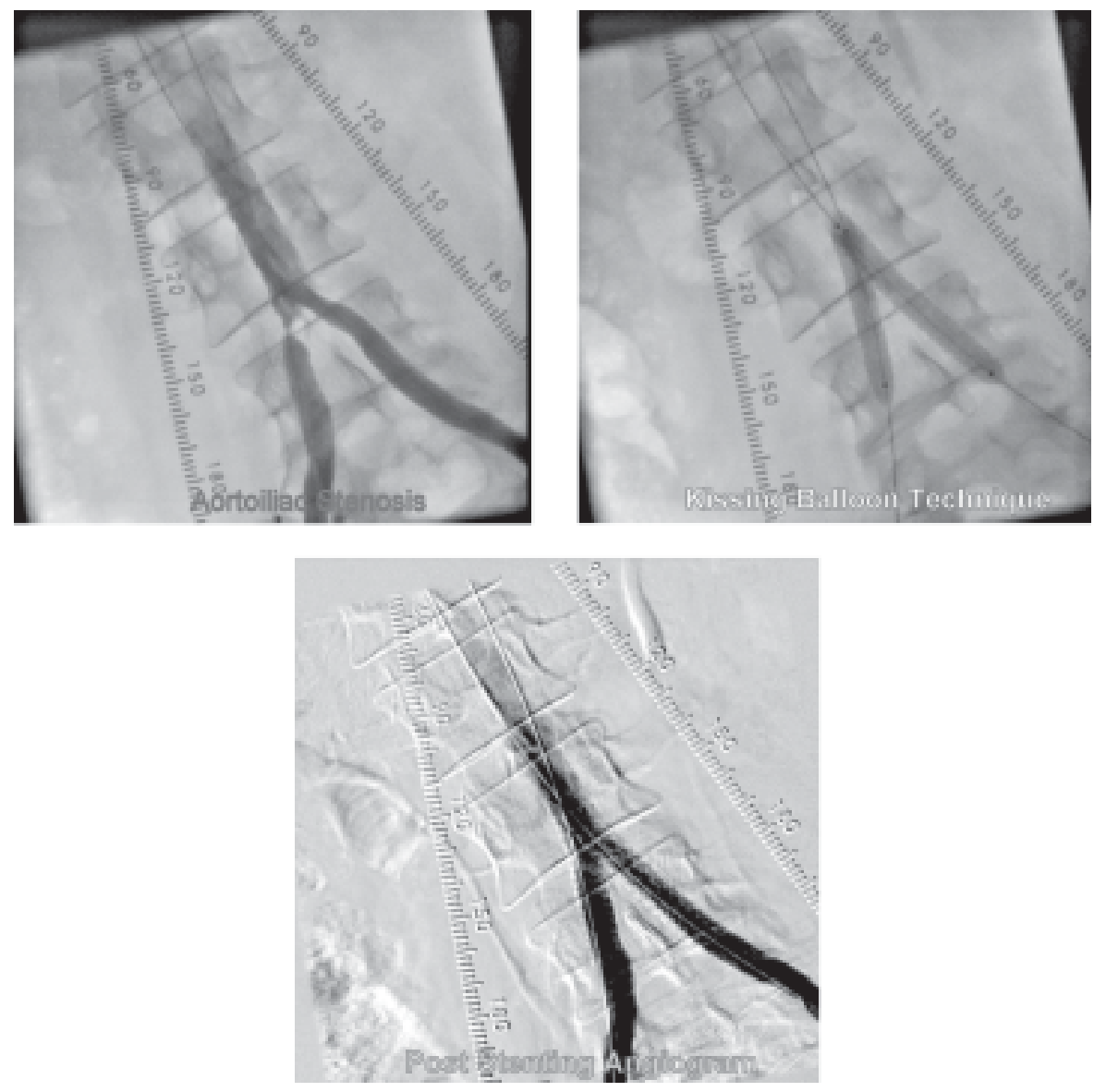

Fig.-1: Kissing stent technique in aortoiliac stenosis. 

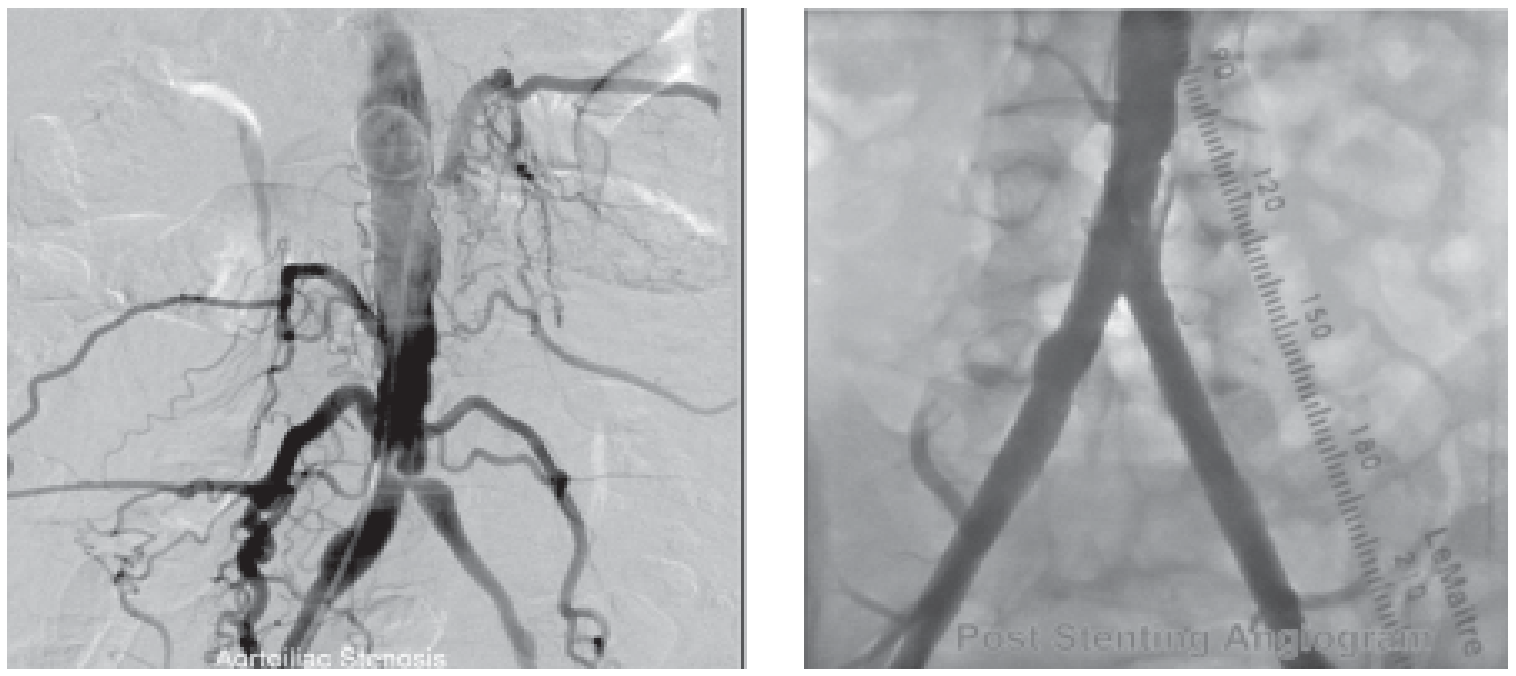

Fig.-2: Kissing stent technique in aortoiliac stenosis.
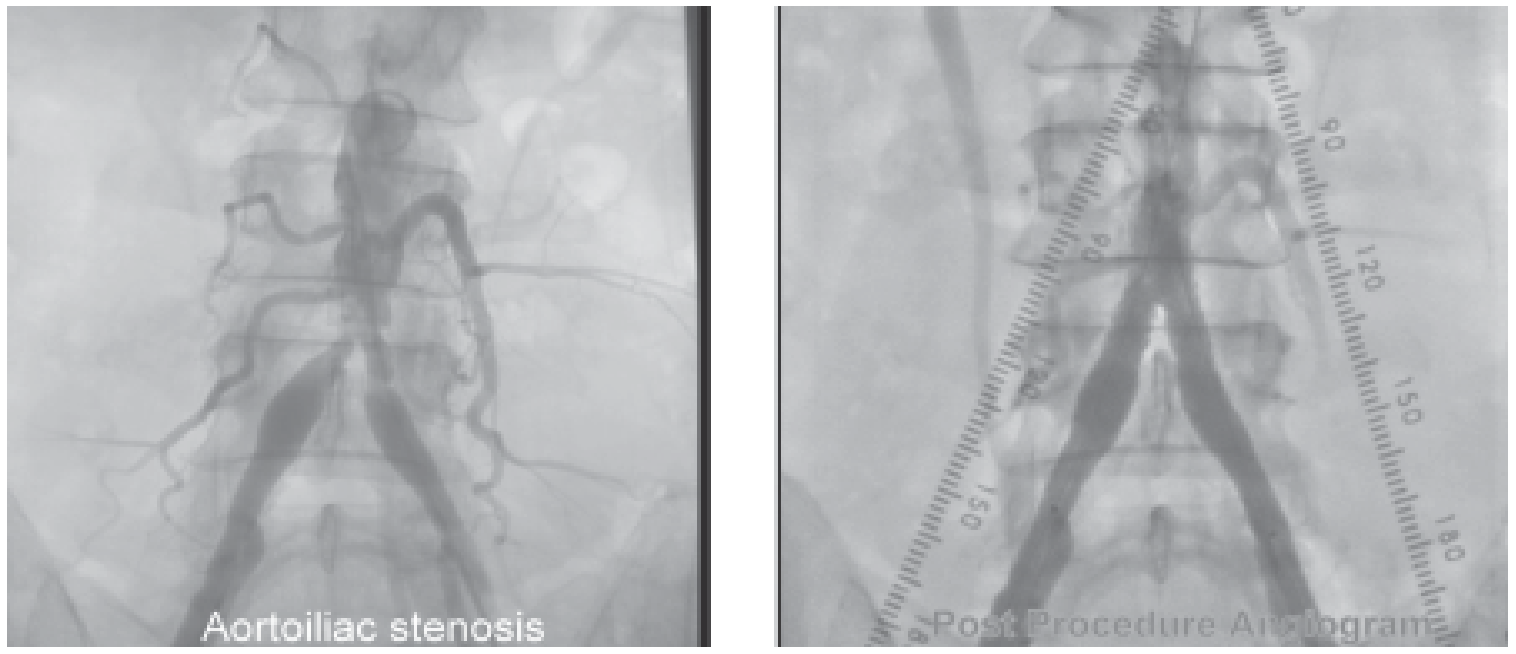

Fig.-3: Kissing stent technique in aortoiliac stenosis.

\section{Result:}

Patient and lesion characteristics In this study total 34 patients had aortoiliac kissing stents.

Table-I

Baseline characteristics. $(n=34)$

\begin{tabular}{lcc}
\hline Characters & Number & Percentage \\
\hline Gender & 29 & \\
Male & 5 & 15 \\
Female & & \\
Risk Factors & 8 & 23 \\
Diabetes mellitus & 25 & 73 \\
Smoking & 12 & 35 \\
Hypertension & 6 & 18 \\
Hyperlipidaemia &
\end{tabular}

According to Trans-Atlantic Inter-society Consensus (TASC) classification 27 (79\%) patients had type A lesions, 4 (12\%) type B, 1 (3\%) type C and 2 (6\%) type D.

Table-II

Lesion characteristic according to TASC guideline. $(n=34)$

\begin{tabular}{lcc}
\hline TASC Type & Number & Percentage \\
\hline A & 27 & 79 \\
B & 4 & 12 \\
C & 1 & 3 \\
D & 2 & 6 \\
\hline
\end{tabular}

TASC, Trans-Atlantic Inter-Society Consensus Lesions were described using conventional catheter angiography. 
Table-III

Clinical status of limb and stents used.

\begin{tabular}{lcc}
\hline TASC Type & Number & Percentage \\
\hline Clinical status ( $\mathrm{n}=34)$ & & \\
$\quad$ Claudication & 25 & 73 \\
Critical limb ischemia & 9 & 27 \\
Stents used ( $\mathrm{n}=68)$ & & \\
Balloon expandable & 52 & 76 \\
$\quad$ Self expandable & 16 & 24 \\
\hline
\end{tabular}

Technical and clinical success was achieved in all patients. During intervention, lesions were crossed ipsilaterally in all patients. In most patients (30,90\%), direct stenting was performed but $4(10 \%)$ required predilatation.

\section{Complication:}

Following the interventions, major complications occurred in 2 cases (cholesterol embolisation syndrome, groin hematoma). Cholesterol embolisation syndrome was managed conservatively but took prolonged hospitalization. Groin hematoma required surgical correction. One minor complication injury to a branch of external iliac artery required prolongs balloon dilatation of external iliac artery. Five patients died during follow-up period. There was no mortality due to procedure itself or its complication.

\section{Follow-up:}

Follow-up period was between 1 month and 72 months. In this series surveillance was not upto satisfactory level. When patients did not attend willingly, they were interrogated over telephone. All the patients except deceased attended for follow-up during initial 12 months. Later on $45 \%$ patients attended physically and rests were contacted over telephone. Restenoses were detected in 5 patients and successfully treated with balloon angioplasty.

\section{Discussion:}

Percutaneous transtuminal angioplasty for aortoiliac disease has been considered as contraindication because of the risk of occlusion and embolization. ${ }^{4-7}$ With the initial utilization of double balloon ${ }^{4,5}$ and subsequent introduction of kissing stent ${ }^{6}$ technique such lesions can now be safely and effectively treated endovascularly. Primary concern about kissing stents is the lack of contact between the vessel wall and the opposing stents, which may prevent endothelialization and cause thrombosis or hemolysis ${ }^{6}$ or induce intimal hyperplasia owing to variations in the wall shear stress ${ }^{8}$. Despite these concerns early results of aortoiliac kissing stents were promising.

In the aortoiliac region, as elsewhere in the body, the type of stent is usually chosen based on lesion characteristics, location, vessel tortuosity, and the profile of the stent. However, other factors, such as ease of deployment, familiarity of the physician, cost, and availability are also taken into consideration. ${ }^{9}$ In our patients, stent selection was primarily based on lesion characteristics; for long lesions, occlusions, or those located in tortuous vessels, we preferred self-expanding stents, while we used balloonexpandable stents for short, focal lesions or for eccentric, calcified lesions that are prone to recoil.

\section{Limitations:}

This is a retrospective study which is subject to biases regarding patients and lesions. Secondly, although the patients were actively invited to follow up examination, there were gaps in the follow up schedule. The number of patients in our study is small. So the outcome of this study should be regarded with caution.

\section{Conclusion:}

Kissing stent implantation is a safe and alternative treatment for aortoiliac disease. It is cosmetic, requires short hospital stay. No incision, regional or general anesthesia is needed.

\section{References:}

1. Szilagyi DE, Elliott JP, Smith RF. A thirty-year survey of the reconstructive treatment of aortoiliac occlusive disease. J Vasc Surg. 1986;3:421-36.

2. de Vries SO, Hunink MG. Results of aortic bifurcation grafts for aortoiliac occlusive disease: a metaanalysis. J Vasc Surg. 1997;26:558-69.

3. Oertli D, Wigger P, Landmann J, et al. Long-term results after open and semiclosed thromboendarterectomy for aortoiliac occlusive disease. Eur J Vasc Endovasc Surg. 1996;11:432-6.

4. Tegtmeyer CJ, Kellum CD, Kron IL, et al. Percutaneous transluminal angioplasty in the region of the aortic bifurcation. The two-balloon technique with results and long-term follow-up study. Radiology. 1985;157:661-5.

5. Insall RL, Loose HW, Chamberlain J. Long-term results of double-balloon percutaneous transluminal angioplasty of the aorta and iliac arteries. Eur J Vasc Surg. 1993;7:31-6.

6. Palmaz JC, Encarnacion CE, Garcia OJ, et al. Aortic bifurcation stenosis: treatment with intravascular stents. J Vasc Interv Radiol. 1991;2:319-23.

7. Mendelsohn FO, Santos RM, Crowley JJ, et al. Kissing stents in the aortic bifurcation. Am Heart J. 1998;136:600-5.

8. Saker MB, Oppat WF, Kent SA, et al. Early failure of aortoiliac kissing stents: histopathologic correlation. J Vasc Interv Radiol. 2000;11:333-6.

9 Leung DA, Spinosa DJ, Hagspiel KD, et al. Selection of stents for treating iliac arterial occlusive disease. J Vasc Interv Radiol. 2003; 14:137-52. 